\title{
One hundred years of extensional flow *
}

\author{
Christopher J.S. Petrie \\ School of Mechanical \& Systems Engineering, University of Newcastle upon Tyne, \\ Newcastle upon Tyne, NE1 7RU, UK
}

\begin{abstract}
This historical review takes a few selected issues from the rheological studies of extensional flow that fill the literature, starting with extracts from the seminal papers of Trouton (Proc. Roy. Soc. A77 (1906) 426-440) and Fano (Archivio di fisiologio, 5 (1908) 365-370). Work in the first half of the twentieth century on spinnability and extensional viscosity measurement is highlighted, followed by a discussion of the blossoming of studies on extensional flow. As a case study, a project on anti-misting additives in aviation fuel is taken; whether the rheology or the politics is the more interesting is an open question. Finally some current issues surrounding spinnability and other extensional flow phenomena are discussed.
\end{abstract}

Key words: Trouton, Fano, spinnability, extensional flow, history, review PACS: 83.50.Jf, 83.85.Rx, 01.65.+g

\section{Introduction}

This paper celebrates the contributions of Trouton in 1906 [1] and Fano in 1908 [2] to rheology and to extensional flow in particular. An account of the genesis of this partial (in both senses of the word) historical review may give the reader some idea of what to expect. There were four main sections in the talk given at the Lake Vyrnwy conference: history (1900-1950), extensional flow in the literature, a practical case study, and a few remarks on extensional viscosity and unsteady flows. In writing and discussing a draft paper it became clear that the last section was important and this has been developed in a companion paper [3]. The case study (Section 4) on the effect of additives in

ऋ Based on part of the talk delivered at the INNFM conference, Lake Vyrnwy, Wales in March 2005 with the title "Ninety-nine years of extensional flow".

Email address: Chris.Petrie@Newcastle.ac.uk (Christopher J.S. Petrie). 
reducing the risk of fire from aircraft fuel spillage generated much interest; it is perhaps as much a case study in politics as in rheology and turns out to have much less than anticipated to do with extensional flow. Part of the account of extensional flow in the literature consisted of some rather naïve counting of occurrences of key words and this has been removed (but is available on the web for anyone interested [4]). The first half of this paper is now an historical review covering Trouton, Fano and then early work in the two areas inspired by them, spinnability and viscosity measurement.

For those who wish to pursue historical researches in more detail, chapter 1 of the first book in this area [5] and parts of chapters 6 and 7 in the history by Tanner \& Walters [6] are useful secondary sources. Two papers presented at major conferences $[7,8]$ fill in other details and there are reviews by Denn [9] on fibre spinning and McKinley \& Sridhar [10] on filament stretching. An earlier review by Denn [11] is also well worth reading, particularly on the subject of the effect of multiple relaxation times. Instabilities in extensional flow have received much attention with reviews from 1976 [12-14] and more recently [15-17]. Books by Middleman [18] and Yarin [19] discuss, among other things, the stability and breakup of an axisymmetric Newtonian jet and offer a link to literature on much high quality experimental and theoretical work on Newtonian liquid jets.

There are some obvious omissions from this review which we itemize here with a few references and minimal discussion.

* Polymer processing applications: we direct the reader to books such as those of Pearson [20,21] and Middleman [22] on polymer processing and Ziabicki $[23,24]$ on fibre spinning (which is also reviewed by Mewis and Petrie [25]). It is worth noting the key challenges in polymer processing that Kurtz identified [26] and this author's updated list [27] in which all the key challenges involve extensional flow, to some extent at least.

* CFD and the variety of numerical simulation techniques: see two early books in this field $[28,29]$ and some more recent books and reviews [3035]. The most prominent extensional flow application is to contraction flows; fibre spinning [29, Chapter 6] and film blowing [29, Chapter 7] are the pre-eminent polymer processing operations involving extensional flow.

* Experimental techniques for extensional rheometry: for polymer melts the fundamental problems of extensional rheometry seem to be solved and are well reviewed by Meissner [36], see also Dealy [37]. For polymer solutions there are reviews by Gupta and Sridhar [38] and more recently McKinley and Sridhar [10]. Fuller [39] has developed optical methods and use of stagnation point flows.

More serious is the omission of discussion of flow classification and the question 
of what is an extensional flow [5, Chapter 4]. Ziabicki [40] was the first to point out the significance of the difference between shearing and extension for polymeric liquids. Keller and Odell [41] reviewed a good deal of experimental work which used extensional flow to elucidate the physics of macromolecules in solution. The ability of a flow to stretch and align macromolecules in solution or fibres in suspension has led to an approach to flow classification which uses the terms "strong" and "weak" for flows (corresponding to extension and simple shear respectively) $[42,43]$. Credit for raising the issue of floworientation of macromolecules appears to be due to Nitschmann and Schrade [44] in their work on the use of fibre spinning - the first since Trouton.

From the work of mathematicians came a formal definition of an extensional flow by Coleman [45] which has been discussed by this author [5]. Using the polar decomposition theorem applied to the deformation tensor, $\mathbf{F}$,

$$
\mathbf{F}(t)=\mathbf{R}(t) \mathbf{U}(t)
$$

defines the (orthogonal) rotation tensor, $\mathbf{R}$, and the (positive definite symmetric) right stretch tensor, $\mathbf{U}$. A flow is extensional if there is a fixed orthogonal coordinate system in which $\mathbf{U}(t)$ has diagonal components (for all $t$ ) [45]. A pure stretching flow is one for which $\mathbf{R}(t)=\mathbf{I}$ for all $t$ and there is almost a proof [5] that a flow is extensional if and only if there is a frame of reference in which it is both irrotational and a pure stretching flow. Note that the definition of extensional here is frame indifferent but neither irrotational nor pure stretching is frame indifferent.

A related question is whether exponential shear [46, Section 2.3] should be classified as an extensional flow or at least as a "strong" flow. The original idea of exponential shear may be traced back to Lodge and Meissner [47] who advocate comparing shearing and extensional flows in which the history of the principal strains is the same. In fact Lodge and Meissner suggested using an extensional flow experiment in which the principal stretch ratio, $\lambda(t)$, is the same as in shear (where it has a roughly linear dependence on time). This would be, for example, a tensile test in which the length of the specimen grows at a constant rate (the ends separate with constant velocity). Such experiments were carried out by Vinogradov [48] but, as far as the author knows, no comparison between such a flow and simple shear has been explored. We might ask whether such a flow - constant velocity extension - is a "weak" flow.

In steady extension, $\lambda(t)$ grows exponentially with time, so consideration of a shear flow with the same deformation history as in extension leads to the flow called exponential shear. This idea was developed explicitly in $1987[49,50]$ with the view that exponential shear is a strong flow. A variety of choices has been made for the appropriate function to describe the material response 
(as a ratio of stress to rate of strain which may be regarded as a transient viscosity function). This has led to different conclusions and the most recent are that the flow is weak (Venerus [51]) or strong (Kwan et al. [52]) while Graham et al. [53] are equivocal, finding from simulations that exponential shear stretches molecules as in steady simple shear and orients them as in uniaxial extension. This highlights an important problem with flow classification: what is important, molecular stretching or molecular orientation or both?

Another topic which has not borne fruit is a general study of "nearly extensional flows". The idea was originally put forward by Metzner [54] with his proposal of the "extensional primary field" approximation and there is a brief review by this author [8] of attempts between 1978 and 1982 (by Pountney \& Walters, Huilgol and Powell \& Schwarz) to develop a formalism to parallel the lubrication approximation for shear flows. The most important flows that combine shear and extension are converging and contraction flows and there has been much experimental and computational investigation of contraction flows [55,31]. There has been work on lubricated converging channel flows [56], which does not seem to have developed as a widely used technique, and on unlubricated converging channel flows [57]. Measurements on converging and contraction flows are used to estimate some sort of extensional viscosity for polymeric liquids, generally on the assumption that extensional stresses far exceed shear stresses [58,59] (see also [3, Section 4]).

\section{Early days of rheology}

Much of the early work on extensional flow has been reviewed by the author in two sources which are now not so easy to obtain [5,7], the 1979 book devoting a chapter of 20 pages to a historical introduction and the 1980 paper supplementing this, mainly with reference to polymer melts. Sections 2.1 and 2.2 reproduce and augment some of the information in the book [5].

In this section we trace interest in extensional flow through the period leading up to the coining of the word "rheology" [60] and the foundation of the first societies of rheology in the USA, Britain and the Netherlands, up to the time when extensional rheometry had clearly emerged and a number of techniques were available. The first advertisement for a commercial extensional rheometer that the author has been able to trace appears on the back cover of the Bulletin of the BSR in 1984 [61] but there are probably earlier examples.

We can identify a few areas where extensional flow was used in the period from Trouton and Fano up to the serious interest in polymeric liquids in the 1960s and 1970s. 
- Spinnability (Section 2.3).

- Biological applications (Section 2.3).

- Viscosity determination (and study of creep) (Section 2.4).

- Technical applications, e.g. in the glass industry (Section 2.4).

- The artificial fibre industry.

We do not have space here to devote to the early development of the artificial fibre industry; the reader is directed to Ziabicki's book [23] and a paper by White [62]. We also omit discussion of many applications where spinnability is undesirable, e.g. ink-jet printing, aerial spraying, paint spraying. Such applications require "sprayability" (in some sense the inverse of spinnability) [5, p.19] - the word escaped the index of that book. The case study below 4 clearly involves such an application.

\subsection{Trouton}

The first study of extensional flow is generally taken to be Trouton's 1906 paper [1] though Trouton's intention was to obtain the viscosity of a Newtonian liquid.

Frederick Thomas Trouton was born in Dublin in 1863 where he studied, graduating MA and DSc and receiving a large Gold Medal before being appointed Assistant to G.F. Fitzgerald in 1884. He was elected FRS in 1897 and was appointed Quain Professor of Physics in the University of London in 1902 until ill health forced his retirement in 1914. He was mentally active until his death in 1922. While still a student he published a note on what his obituary [63] describes as the relation between the molecular latent heats and boiling points of liquids "known to every physical chemist as Trouton's law" [64]. It is interesting to note that in the obituary published by the Royal Society, Trouton's 1906 paper and his coinage of the term "coefficient of viscous traction" are not mentioned at all and he is Trouton of "Trouton's Law" and not of the Trouton Ratio. This seems the more surprising as his obituary runs to six pages, while Fellows such as Venn of the "Venn Diagram" or Heaviside of the "Heaviside Function" and "Heaviside Layer" are each given a modest two pages in the same issue of the Proceedings [63]. Trouton's most well-known work, following his mentor, Fitzgerald, was in electromagnetism and the relative motion of the Earth and the ether, leading to the Trouton-Noble experiment which paralleled that of Michelson and Morley and had the same negative and highly significant result.

His interest in "the viscosity of quasi-solids" and the ingenuity he displayed in investigating this is noted in the obituary [63]. With E.S. Andrews [65], he reviewed briefly some methods available for determining the viscosity of 
highly viscous materials:

(a) The girder method (as applied to measuring the viscosity of ice)

(b) Methods depending on direct extension and compression

(c) Stokes' method (falling ball)

(d) The torsion of a cylinder

and concluded that the first two did not "lead readily to numerical determination of the coefficient of viscosity." He implicitly contradicted this conclusion, something we should applaud, in carrying out his later work [1]. The third method was used in 1904, but required X-rays in order to track the motion of the falling ball. The main method used here [65], for determining the viscosity of pitch, molten glass and shoemaker's wax, was the torsion of a cylinder. A related paper with A.O. Rankine [66] investigated creep of lead wires. In both papers the elastic and viscous parts of the material response were noted.

Trouton turned to extensional flow in his 1906 paper "On the coefficient of viscous traction and its relation to that of viscosity" [1]. This covers a remarkable number of techniques and issues. Trouton's intention was to obtain the viscosity of a highly viscous liquid and he was aware of non-Newtonian fluid behaviour. He seems to be using an analogy with solid mechanics, with shear modulus and Young's modulus corresponding to viscosity (in shear, from the fundamental definition) and extensional viscosity (which Trouton called the coefficient of viscous traction) respectively.

Trouton discussed four experiments:

(A) "Traction experiments" - the stretching of a uniform cylinder.

(B) "Axial compression of cylinders".

(C) "Flow of a stream descending under its own weight" - gravitational spinning.

(D) "Sagging of a horizontal beam" - the girder method, (a) above.

Trouton did the theory (which many people in the next 40 or 50 years appeared to ignore) and came up with the (by now familiar) ratio of 3 between extensional and shear viscosity - the Trouton ratio. This ratio is a necessary consequence of geometrical invariance for an incompressible material with a linear dependence of stress on rate of strain. Trouton showed two derivations of the result, one that will be familiar from solid mechanics, involving the expression of the state of stress in terms of shear stresses and a hydrostatic pressure, and one more in line with a fluid mechanical way of thinking, calculating principal stresses and using the zero stress boundary condition at the free surface of the stretching cylinder. For anyone who is surprised to find the beam bending experiment $(D)$ in a discussion of extensional flow, the parallel with the occurrence of Young's modulus, E, rather than the shear modulus, $G$, in classical beam bending formulae may be helpful. 

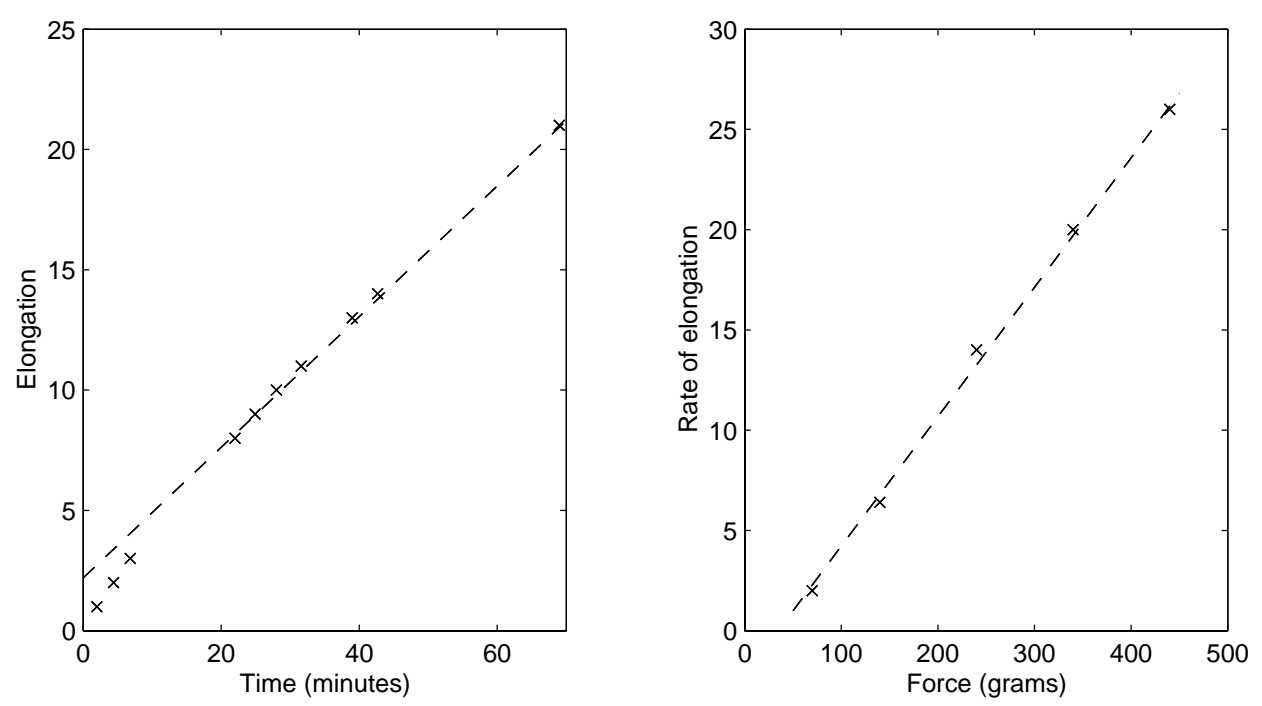

Fig. 1. Trouton's results for pitch: (a) Elongation against time, (b) Rate of elongation against force (grams). (Values from [1, Tables I, II])

In his discussion of traction (A), Trouton made it clear that he understood the importance of uniformity of stretching, of compensation for the effect of gravity and of devising a good technique for applying the tractional force. His results for pitch are shown in Fig. 1 where the elongation is in arbitrary units. These show steady elongation over nearly an hour after a ten minute start-up period, and Newtonian behaviour apart from a non-linearity in response at very low applied force. The slope of the graph gives the extensional viscosity for which Trouton found the value of $4.3 \times 10^{1} 0 \mathrm{cgs}$ units $\left(4.3 \times 10^{9} \mathrm{Pas}\right)$ and for the same material the shear viscosity of $1.4 \times 10^{1} 0 \mathrm{cgs}$ units $\left(1.4 \times 10^{9} \mathrm{Pas}\right)$. Trouton tested the ratio of extensional viscosity to shear viscosity with several materials with viscosities from the above value down to $7.6 \times 10^{5} \mathrm{cgs}$ units (in extension). He used shoemaker's wax and also pitch mixed with tar to lower the viscosity somewhat and in eight cases found the ratio between 2.91 and 3.60 which is quite satisfactory. Comparison with the other extensional flow methods was also satisfactory as far as it was checked.

\subsection{Fano}

Fano's 1908 study [2] of the thread-forming capabilities of liquids is as significant as Trouton's work on viscosity measurement. It is perhaps closer to issues that motivate rheologists today and it certainly addresses questions that are not, even now, quantitatively understood. Even at a qualititative level, we cannot fully answer the question of why one liquid forms threads and another does not. This is the topic of "spinnability": is a liquid "spinnable" in the sense that it forms long persistent threads when drawn out in some way? The ideas of elastic and viscous responses of materials, of separating these in some 
way and of connecting them to observations on phenomena such as thread formation, atomization (see Section 4) and flow instability, are recurrent themes in later work.

Giulio Fano was born in Mantua in 1856, held chairs in physiology at Genoa (from 1884), Florence (from 1894) and Rome (from 1916) and died in 1930 [67]. He was prominent in international physiological circles, deeply concerned with the philosophy of science and also was a member of the Italian Senate from 1911 till his death. Like Trouton, his rheological fame rests on a single paper which appears somewhat peripheral to his main interests; these included the effect of ductless glands and hormones on physical and psychological makeup. He also had some trenchant things to say about the philosophy of science which Pogliano [67] quotes - our translation:

Let us say to those who spend their lives in the laboratory and have submitted their will to the demands of (excessive attention to) technical detail: the first instrument that they must learn to handle is their own brain; without general concepts and without an intellectual technique they become only sterile empiricists groping in the dark; with only factual data, unaccompanied by knowledge of the history and the logic of ideas, one can be neither scientist nor expert nor professional.

and

Hypotheses give an ideal to scientific research ... We do not follow those who want to eliminate speculation in science; without it, research is empiricism which entrusts to chance its potential for bearing fruit, as the pollen of flowers is abandoned to the blind mechanics of the wind. How many seeds are lost in this manner!

Fano's 1908 paper, "Contribution to the study of thread-forming materials" [2], is a landmark as important as Trouton's paper. Fano's name is now associated with the experimental arrangement which he devised - Fano flow (otherwise referred to as the "tubeless syphon" or "ductless syphon"), Fig. 2. Fano should also be given credit for a penetrating review of material behaviour in which he highlighted the somewhat neglected (then as now) property of spinnability. He attributed to Ibbertson (no reference given) a list of types of material, classified according to their plasticity (we might say according to their rheology) from gases through mobile liquids, viscous liquids, ultraviscous liquids, plastic solids, ductile solids and brittle solids (this is not dissimilar to Vinogradov's classification associated with rupture [68]). Fano chided Ibbertson for the lack of any mention of thread-forming materials (i corpi filanti). He also took Rotinjanz (no reference given) to task for measuring the viscosity of molten sulphur without taking any account of its thread-forming capacity.

Fano attributed spinnability in biological materials to large molecules in so- 


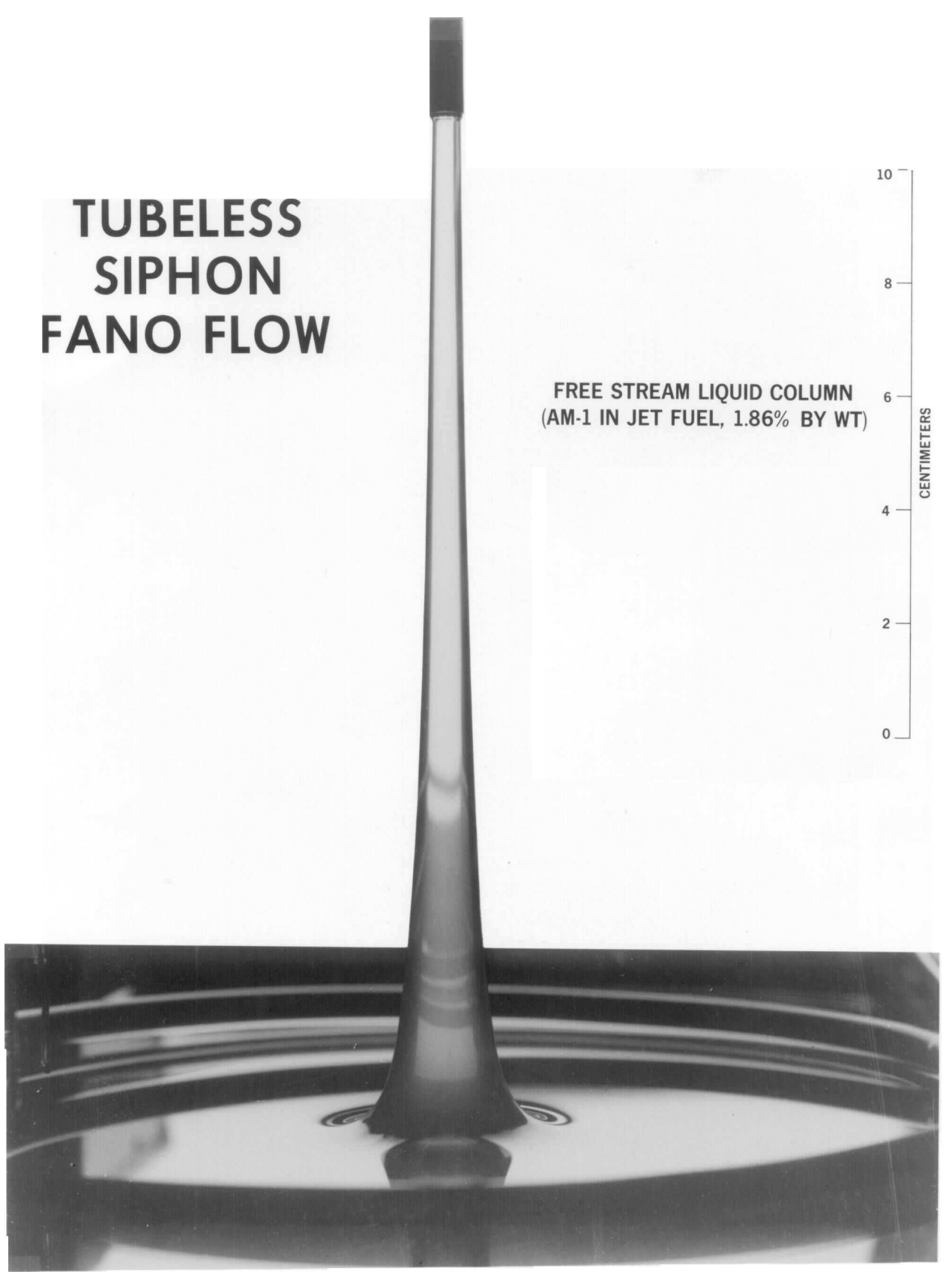

Fig. 2. Fano flow (photo courtesy of S.T.J. Peng and R.F. Landel, reproduced with permission)

lution (polysaccharides and proteins) and noted that filtration reduced spinnability. He reported observing the retraction (elastic recoil) he observed when a thread of liquid is broken. He states [2, our translation]:

Spinnable materials are distinguished above all by the fact that, under suitable conditions, they show elasticity in tension to such an extent that one is led to consider them, in respect of some properties at least, to be more like solids than liquids. 
Among the materials which Fano studied are albumen, saliva, soap solutions and infusions of cactus leaves (Opuntia ficus indica). Among other observations is the note that there was no obvious connection between viscosity or surface tension and the thread-forming ability under investigation. However he did speculate about the formation of an elastic network ("structural scaffolding") in spinnable liquids, raising once again the idea of a combination of elastic and viscous behaviours.

\subsection{Spinnability}

At the inaugural meeting in 1940 of the British Rheologists' Club (now the British Society of Rheology), a discussion on "Rheology in Industry" was led by J. Pryce Jones and among other topics was listed "Spinnbarkeit", but alas no details of the interesting demonstrations were given [69]. There was an air of mystery or of scientific weight added to the idea by the use in the English language literature of the German word "Spinnbarkeit" for spinnability. At around the same time one of the founders of the BSR, Vernon Harrison, wrote (in a paper introducing rheology to the British scientific community [70]) of the rapid progress of rheological research "since it has been found indispensable in many industries". He referred to substances which are "not pure" (and hence traditionally avoided by "the older chemist") and made reference to central rheological ideas such as time scales of deformation. In connection with our theme he wrote:

The list of curious properties of matter which the rheologist is called upon to investigate has by no means been exhausted. For example, there is 'fibrosity', or the property by which certain liquids can be drawn out into long stable threads. The formation of threads of silk and of artificial textiles is dependent on fibrosity.

We also find, in the first issue of the Bulletin [71], an article by Harrison on "Rheology in the Printing Industry". This referred to a number of physical properties of printing inks: yield stress, thixotropy, viscosity, surface tension and fibrosity. These were contrasted to quantities used in the industry:

At present, the control of the rheological properties of inks is still largely effected by the subjective estimates of such qualities as "body", "length" and "tack". These are not simple physical properties, but some combination of them which may or may not have any real bearing on the behaviour of the ink on the machine. One of the first problems of a rheologist who is required to place the grading of inks on a more scientific basis is to analyse these subjective judgements as far as possible. Thus "body" appears to involve mainly a study of anomalous viscosity, "length" denotes the capacity of an 
ink for being drawn out into long, fairly stable threads, and is thus connected with fibrosity, while "tack" is a vague term, but seems to be used mainly to denote the degree of stickiness felt when a film of ink is broken between forefinger and thumb.

The term anomalous viscosity was used at this time (1941) to refer to strainrate dependent viscosity and fibrosity was Harrison's term for spinnability, so that "length" is the quality related to our present discussion.

A paper based on the above-mentioned talk by Pryce-Jones [72] is largely concerned with a thixotropy and uses concentric cylinder geometry (shear flow), but there is a paragraph on "Spinnbarkeit" or "Fibrosity" and it was observed that fibres over one metre long could be obtained from a dispersion of $30 \%$ gum arabic in a $1 \%$ solution of sodium borate. Pryce-Jones reported on a long series of experiments from which he observed that dilatancy (i.e. viscosity that increases with rate of shear) appeared to be essential to spinnability, though not all dilatant systems were spinnable. Spinnable systems also often showed anomalous (i.e. non-Newtonian) surface viscosity.

It may be a reflection of the difficulty in characterizing and explaining spinnability that it disappeared from the rheological literature. We may note the total absence of any mention in Pryce-Jones' later paper [73] where the focus of interest was on shear rheology, the classification of material behaviour and definition of terms such as thixotropy, rheopexy and false-body. The report of a BSR conference on the rheology of proteins in 1956 [74] is similarly silent on extension, dealing with a variety of properties of biological materials and connections between structure in the liquids and rheological properties.

In his 1941 paper [72], Pryce-Jones referred to recent rheological papers on spinnability, citing Erbring [75]. In an earlier series of papers, Erbring [76-78] reported on extensive investigations of spinnability ("Spinnbarkeit" or "Fadenziehens"), for example listing experimental results for sixteen substances (including albumen, plant extracts, soaps and polymers) [76, Section D]. Erbring's summary in the first paper of the series [76, Section F, pp.235-237] included

1. The effect of viscosity, surface tension and structure formation on spinnability in previous publications (from 1908 - 1930) was discussed; there was no clear pattern.

2. An apparatus for the quantitative measurement of spinnability and its dependence on viscosity and spinning velocity was described.

3. In general fibre length increased with spinning velocity and with viscosity. However with high viscosity or high spinning velocity a reduction in spinnability could happen, associated with the delivery of the material to the region of deformation. 
4. Plant extracts showed a maximum in spinnability at intermediate viscosity or intermediate spinning velocity.

5. The measurement of "structure viscosity" (a term due to Ostwald) and "flow elasticity" was carried out but no clear link with spinnability reported.

Erbring listed three quantitative methods for measuring spinnability, that of Fano [2] (measuring the maximum length of column obtained in Fano flow), that of Aggazotti [79] who measured the length of thread obtained when fluid dripped from a pipette and that which he (Erbrring) used. This third method was attributed to Tamman [80], with developments by Jochims [81] and then Erbring [76], and measured the spinnability by the maximum length of a fibre obtained by withdrawing a glass rod or tube from the liquid at a controlled velocity (the spinning velocity).

Zidan [82] showed how difficult it is to characterize spinnability unequivocally. He repeated Fano's experiment with two solutions. A polyacrylamide solution was spinnable according to Fano's criterion, while a viscose solution failed the Fano test even though both solutions were spinnable from the industrial point of view (i.e. they were used to manufacture fibres by spinning). Zidan also claimed that fluids which showed normal stress effects might not be spinnable, even though they passed the Fano test. It may be worth considering these comments alongside the discussion of the additives AM-1 and FM-9 below (Section 4).

D'Arcy Thompson [83, p.12] proposed the term viscidity for spinnability and related this property to the capillary breakup of threads [83, pp.61-66, 75-76]. This is appropriate since, for a liquid to be spinnable, some mechanism must be delaying the onset of the capillarity-driven breakup of the thread into droplets, but does not address the question of what this mechanism might be. Thompson's writings have much to recommend them as a contrast to the scientific writings of today, for anyone prepared to devote a little time to appreciating the leisurely style and careful reasoning which is to be found therein. More direct early applications of extensional rheology in biology may be found in the work of Scott Blair [84] and Clift [85] on the detection of ovulation. These authors, like others discussed above, remarked on an association between the properties of spinnability and flow-elasticity.

Biological applications have returned to centre stage in recent years, with both practical and fundamental motivation. We find interest in the properties of saliva from a dental point of view [86]:

The presence of salivary structural components has been speculated since around the turn of this century (Fano, 1908), ... However, until recently, a structural model for this low-viscosity non-Newtonian body fluid has been 
lacking. In theory, it should be possible to explain the nature of structural elements in fluids such as saliva by the use of rheology.

A recent review by Larson [35] devotes a lot of space to the rheology of DNA molecules in solution and also reports on the use of Brownian Dynamics as a computational tool. Larson is one of the few modern authors to have discussed spinnability [87] during the period when extensional rheometry was making rapid progress (Section 3 below).

\subsection{Viscosity measurement}

The reports of the working party of the Royal Dutch Academy of Sciences in 1935 [88] and 1938 [89] are important foundation documents, although in them attention is devoted principally to simple shear. The chapter by van Nieuwenburg [90], giving an industrial point of view, contains an interesting comment in relation to extensional flow. He wrote, after discussing the determination of viscosity for "difficult" materials, on p. 171:

Reasoning exclusively from a technical point of view, I consider it most urgent that the technique shall be presented with a complete set of different determination methods, for example as have been collected by Saal, but then including compression of cylinders, stretching of threads,

The reader can judge how long it took to realize this aim. He went on [90, pp.171-172]:

and the formulae enabling the technical investigator to calculate not only $\eta$ but also $D$ and $\tau$ (either $\tau_{\text {max }}$. or $\tau_{\text {aver. }}$ ) from the determinations, in order to achieve that in future, far more than at present, a real $D-\tau$ diagram is obtained as a result of a plasticity determination. The behaviour of solid materials, especially that of metals, may not be lost sight of either.

After this we shall have to find out, how in cases of superposition of elastic and plastic deformations the two phenomena may best be distinguished.

We see yet again the idea of separating the elastic and the viscous (which van Nieuwenburg refers to as plastic) response of materials.

The chapters by J.M. Burgers [91] also have some discussions involving extensional flow. Burgers noted a suggestion by van der Waals [92] that one of three mechanisms of internal friction (viscosity) is "the formation of groups, which are elongated when the liquid is in motion". In the discussion of experiments he covered extension of a cylinder, essentially repeating Trouton's derivation of the ratio of 3 for extensional viscosity to shear viscosity. He concluded that: 
stretching experiments will be equally applicable for the elucidation of the properties of a substance as experiments on the shearing motion, especially if they can be performed in such a way that the value of $\sigma$ is exactly kept constant during the process.

(and he cited the work of Andrade [93] on this subject). The separation of material response into elastic and viscous parts was yet again discussed, citing Bingham [94] and Trouton and Rankine [66] on the viscosity of metal wires; much of this was in the context of linear viscoelasticity where addition of the two responses is correct. Burgers also discussed two approaches to compression of a cylinder, lubricated compression which is in effect extension with a negative rate of strain, for which he cited earlier work by G.I. Taylor [95], and compression with adhesion to the end plates which was analysed using the lubrication approximation, in effect as a shear flow, using an approach due to Scott [96]. The other chapters in the First Report [88] on "Colloids" by H.G. Bungenberg de Jong, "Crystalline substances" by W.G. Burgers and J.M. Burgers and "Protoplasm and muscle" by H.J. Jordan are historically fascinating but have no relevance to this review.

The Second Report [89] is more concerned with shear flow, apart from sections in a chapter on "Plastometers" by C.J. van Nieuwenburg which dealt with compression, using Scott's formula and extending this to a material with yield stress, and with extension of threads which "has of old been a common method used in the investigation of the plastic behaviour of glass, of fibres and of metals." He made a connection between non-Newtonian viscosity as a function of rate of strain in uniaxial extension and simple shear where the viscosity function $f(\dot{\kappa})$ in shear corresponds to $\sqrt{3} f(\sqrt{3} \dot{\varepsilon})$ in extension (which we should now express by asking that $f$ be a function of the second invariant of the rate of strain tensor). This result was attributed to Lillie [97] who used it in connection with glass viscosity. Van Nieuwenburg also cited Trouton's extensional flow paper [1] and the book by Bingham [98].

Weissenberg's name is associated with shear flows - the rod-climbing effect and the rheogoniometer. It is of interest to note briefly that his studies did involve extension. Pure shear is mentioned in the abstract [99] of a paper read at a meeting of the British Society of Rheology in Newcastle, halfway through the century we are reviewing. He mentioned interest in irrotational motion with the aim of resolving the complexities arising in simple shear because of the rotation of the principal axes of stresses and strains.

Building on some of this work and owing more than some people acknowledged to Trouton, extensional rheometry became a serious rheological activity in the 1960s. We note that (as has been observed elsewhere [6, p.146]) much of the progress at this time was made in industrial rather than academic laboratories. Early work on polymer melts was carried out by Ballman at Monsanto [100], 
Meissner at BASF [101,36] and Cogswell at ICI [102,58]. The exception to this industrial base for extensional rheometry is the work of Vinogradov in the Soviet Union [103]; many Soviet results were collected in the book [104] and it is a mark of the rapid progress in extensional flow around 1977-78 that the English translation of this book [105] is significantly different from the Russian original. This period is reviewed in more detail in the author's book [5]. On the more practical side we also note the applications from around 1930 in glass technology [97], which persist to this day [106, p. 115].

One interesting difference in presentation of some of the early results for molten polymers (and for polyisobutene at room temperature) is between the simple calculation of stress and rate of strain (e.g. by Ballman, Cogswell, Meissner) and the calculation using separate viscous and elastic parts of the strain (by Vinogradov). As we have noted, the separation of elastic and viscous behaviour has been a recurrent theme, from Trouton and Fano onwards; we discuss this in the companion paper [3, Section 5]. As well as Vinogradov, Meissner was well aware of the importance of elasticity and he measured (and recommended that others measure) elastic recoil on the cessation of extension, a practice which many others adopt today.

\section{Progress in extensional flow}

One important way in which progress was made over two decades was by the organization of a number of conferences and workshops devoted wholly or in part to extensional flow (sometimes under a synonym such as elongational flow or stretching flow). Special issues of this journal, often recording important papers from such conferences, have been devoted to extensional flow since very soon after the journal was founded.

In an earlier review [8] this author wrote of a list of four meetings in Britain followed by four in France that

If this betrays a European bias, which it certainly seems to do, this may reflect the habit of European societies to pick one or two themes for their annual meetings. I am certainly not suggesting an absence of interest or effort on the part of American, Asian or Australian rheologists. Their presence at European conferences gives ample evidence of both interest and effort. The habit in these continents seems to be rather to have sessions on a variety of topics within the national meeting, and these are less obvious to the casual historian.

It is certainly true that many meetings of the Society of Rheology have had sessions on extensional flow: examples are the 1971 meeting in Knoxville with a 
symposium on "Fiber rheology and spinning", the 1975 joint meeting with the Japanese Society of Rheology in Hawaii with a symposium on "Melt spinning and elongational flow", the 1979 Golden Jubilee meeting in Boston with three sessions (out of 41) on "Extension" and this continues up to the present. The Journal of Rheology has not tended to have special issues and the only one traced [107] is in fact on extensional flow, arising out of the above-mentioned 1971 Knoxville meeting. We may also note that the Society of Rheology has devoted its annual course (which it runs prior to its annual meeting) to extensional flow on at least one recent occasion (1998). Another contribution from the Society of Rheology is a report from a nomenclature committee chaired by Dealy concerning material functions in extensional flows (as well as in transient shear flows) [108]. This gives nomenclature officially approved by the Executive Committee of the Society of Rheology in October 1983. A revised version [109] was published a decade later.

The first extensional flow conference session of which the author has detailed information was the British Society of Rheology (BSR) conference on "Multiphase systems and elongational flow", held in Norwich in September 1973 [110]. Authors presenting work there included Cogswell, Ferguson, Mackley, Macsporran, Oliver, Petrie and Vinogradov. Nearly two years later (April 1975) the BSR organized a conference at Shrivenham, jointly with the Società Italiana di Reologia (SIR) which had a session on "Stretching and Compressive Flows" [111]. This attracted the participation of Marrucci, Münstedt and Walters as well several of those who spoke in Norwich.

The BSR conference in Edinburgh in September 1977 led to the first special issue of this journal (on Stretching Flows) [112] followed four years later by an issue [113] derived from the joint meeting of the BSR and SIR in Newcastle in September 1981. Earlier in 1981, the first of a series of highly successful workshops on extensional flow was held at Ross Priory in Scotland. In passing we record that the other notable (and, arguably, more successful) series of rheological workshops is that on numerical simulation [6, p.195].

The series of international workshops and conferences on extensional flow continued in France with La Bresse in 1983 and Chamonix in 1988 [114]. In the report on the Chamonix event, Walters recorded that after the La Bresse workshop there was a general consensus that

the field had reached a stage where little of fundamental novelty was forthcoming and no plans were made to hold another conference.

However, within three years a collaborative project on extensional flow had been funded by the EEC (now the EU) which led to the meeting in Chamonix. The variety of techniques and materials discussed there highlighted the need for consistent ways of measuring extensional properties of materials. This 
led to a most important decision concerning the comparison of techniques for measuring the extensional viscosities of polymer solutions, namely to use the same solution in as many different extensional rheometers as possible. The test fluid "M1" was prepared by Sridhar in Monash University and a meeting arranged at Combloux in 1989 [115] to discuss the results. The best known outcome of the Combloux meeting is the confusion illustrated in a chapter on extensional property measurement [56, Fig. 2.1] which we discuss in the companion paper [3, Section 4].

Results for the different test fluid, "A1" (prepared in Aberystwyth) were discussed at Villard-de-Lans in 1991 [116]; this fluid is shear thinning, in contrast to the constant viscosity in shear for the "Boger fluid", "M1". Results for a third fluid, "S1" (prepared in Strathclyde) were reported at Fontevraud in 1993 [117]; in this case the emphasis was not on extensional flow, but on how fluid rheology varies from dilute solution through concentrated solution to melt. There are four papers discussing extensional flow properties. There is no evidence of any greater consistency between results for different methods for any of these three test fluids.

The message from the work with the these test fluids in so many laboratories is that for such fluids we do not obtain a straightforward extensional viscosity as a function of rate of strain. The basic reason for the variety of results obtained is that none of the experiments involved the steady flow that is specified in the definition of extensional viscosity. Any attempt to introduce the concept of a "transient extensional viscosity" or extensional stress growth function is not useful without specification of the details of the flow. This important issue is discussed at length in the companion paper [3].

\section{Case study: polymeric additives and atomization}

A paper by Peng and Landel [118] is the last in a series on the rheology of jet fuel (kerosene) with additives, which formed part of a programme of research on antimisting kerosene (AMK) as a way of decreasing fatalities in post-crash aircraft fires. The paper seeks to correlate rheological behaviour with flammability test results for jet fuel with and without an added anti-misting agent. Fuel is ejected from the front of a wing section into a 120 knot airflow, with a torch ignited under the wing section. The experiments are photographed one second after the release of the fuel. The results are spectacular, showing a fireball engulfing an wing section when jet fuel is used with no additive (Fig. 3 (a)) and no observable fire under the same conditions when the fuel has a small $(0.4 \%)$ concentration of the FM-9 additive (Fig. 3 (b)). The material studied is jet fuel with FM-9 (an ICI product described as a time-dependent inverse Bingham material - it is completely Newtonian up to a critical shear 


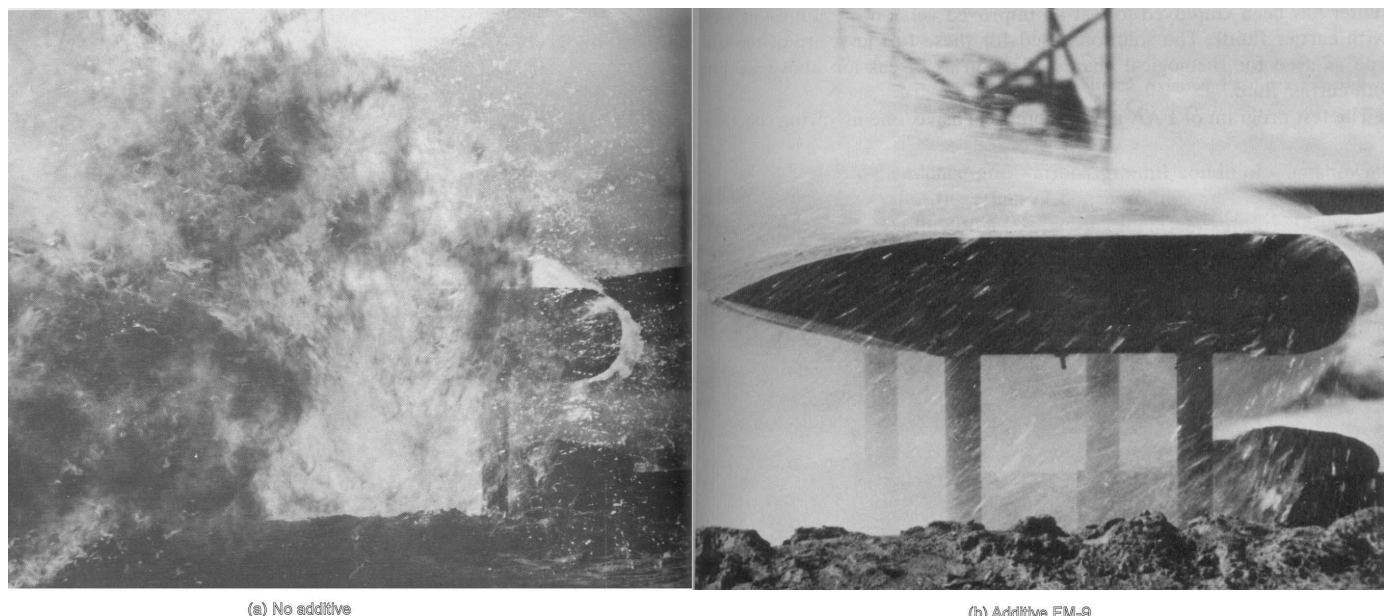

Fig. 3. Flame propagation: (a) no additive, (b) FM-9 additive ([118, Figs. 9 \& 8])

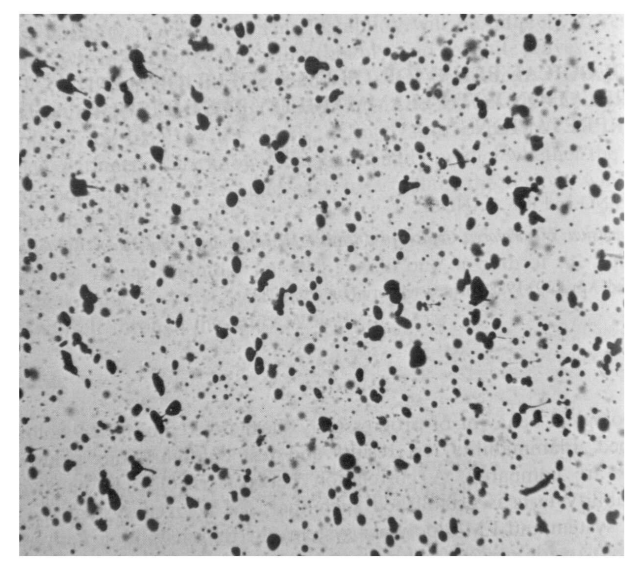

(a) Unmodiffed funel

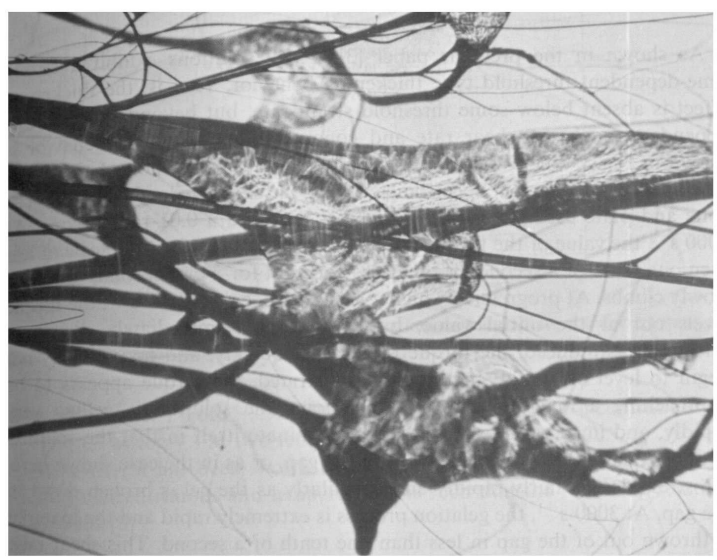

(b) Fuell with AM-1

Fig. 4. Atomization of aviation fuel: (a) no additive, (b) AM-1 additive ([118, Figs. $1 \& 2])$

rate at which it forms a gel). A different solution, jet fuel with AM-1, was used in the same authors' earlier Fano flow experiments, [119] (see also Fig. 2 above) and the two solutions' properties are discussed in the 1983 paper [118]. (AM-1 is a Conoco product with MW of the order of 5 million which has been used as a drag-reducing agent; the polymer is not specified in the reference cited.) An important difference is that the FM-9 solution does not form an inverted syphon like AM-1 and so it was not possible to measure an extensional viscosity. The conclusion was that anti-misting behaviour, which both solutions show, arises from different mechanisms. In the study of flammability, a comparison of dispersed fuel, with and without the additive AM-1, subject to a 100-110 knot air flow is shown (Fig. 4). It is observed that the major difference between the fluids is between well dispersed droplets for the neat fuel, a persistent filamentous structure with the additive AM-1 and large droplets with FM-9. This invites interpretation in terms the thread-forming capability 
of the fuel with additive AM-1 and in terms of the gel-like behaviour with FM-9. Both behaviours can be described as involving flow-induced elasticity, but it is important to be aware of the different mechanisms.

There is more to the story than this, however, arising from the highly important application with its potential to save lives, issues of practical engineering and perhaps of politics. The year after the publication [118] a full-scale test was carried out by the FAA and NASA. Reports of this are accessible on the internet $[120,121]$ as are photographs and film of the "Controlled Impact Demonstration", as it was officially known (the acronym CID lent itself to an obvious alternative interpretation, "Crash in the Desert") $[122,123]$ and unofficial and even irreverent comment can be found on the internet.

As a summary of the test and its consequences, we can do no better than an edited extract from a review [124] of "The Golem at Large: What You Should Know About Technology" by H. Collins and T. Pinch:

... a staged crash organized by the American Federal Aviation Agency in which a (radio-controlled) Boeing 720 filled with dummy passengers and with special kerosene designed to prevent fire after the impact (one of the chief causes of death in such crash landings). The demonstration, however, went horribly wrong when, after a few seconds following the impact, the plane burst into flames!

The airplane experiment had been conducted several times, with success. But for the public demonstration the FAA wanted extreme conditions, and went through the trouble of, for example, installing a metal cutter to cut through the wings and fuel tanks (something that does not normally happen in real crashes). To which it must be added that the radio operator actually lost control of the plane right before landing, resulting in a lateral slide of the aircraft. In other words, the conditions of the crash were novel and significantly worse than the average conditions under which the new fuel was designed to operate.

An experiment that doesn't "work" is actually very useful for the scientist because it leads to learning about the conditions that led to the failure. However, its (negative) emotional impact on the general public can be overwhelming and lead to halting potentially useful research (as in fact happened with the kerosene fuel).

This quotation is misleading if "The airplane experiment had been conducted several times" is taken to mean that other planes had been flown and crashed, since the CID was the first (and only) full-scale, engines running, flight test.

When we examine the test in detail we can take the view that, while the conclusion that the idea should not be implemented is the right one, the reasoning that is given can be disputed. I am indebted to Bob Landel for his 
comments on the test and its interpretation [125], though of course the words here are my responsibility. The snag which undermines the idea of AMK is that while the properties of the fuel with additive are great for the suppression of misting and reduction in flammability after a crash, the same properties (or some of them) render AMK unsuitable as a fuel for the jet engines. Hence use of AMK requires first the blending of FM-9 with the fuel supplied to the aircraft and then the restoration of the AMK to useable jet fuel before it is supplied to the jet engines. Some text from a NASA web site [126] refers to this:

The additive, FM-9, a high-MW long-chain polymer, when blended with Jet-A fuel had demonstrated the capability to inhibit ignition and flame propagation of the released fuel in simulated crash tests. This anti-misting kerosene (AMK) cannot be introduced directly into a gas turbine engine due to several possible problems such as clogging of filters. The AMK must be restored to almost Jet-A before being introduced into the engine for burning. This restoration is called "degradation" and was accomplished on the Boeing 720 using a device called a "degrader." Each of the four jet engines had a "degrader" built and installed by General Electric to break down and return the AMK to near Jet-A quality.

A film clip [127] shows the impact from behind the plane, with the source of the fireball clearly very close to the right engine after the impact of that; further text from the same NASA web site [126]:

Moments after hitting and sliding through the wing openers the aircraft burst into flame, with a spectacular fireball seen emanating from the right inboard engine area.

gives the same information. The idea of the "wing openers" is described by Landel [125]:

Two narrow steel towers were constructed in a shape somewhat reminiscent of an axe and placed such that when the aircraft landed and rolled between them the sharp blades would rupture the wing tanks between the fuselage and the engine on both sides of the plane. The plane would be traveling at its normal landing speed. The outpouring fuel would spew out, be blown back over the still running engines, but should not ignite.

On the far side of the plane from the viewing area, as recorded by another camera [125]:

the footage showed the intended wing tank rupture and the emission of a haze of particles, of slugs, and of a large chunks of "fuel". Moreover, the individual windows and the paint stripe along the plane side could clearly be seen! Not at all a light-scattering fog of fine particles. Only a few wisps 
of fire, which did not propagate. The additive worked as described and intended on that side

Landel's report on this [125] is that because the plane was slightly skewed, the right wing opener hit the right engine as well as the fuel tank. The fuel line was ruptured between the degrader and the engine so that, in effect, normal jet fuel was spilled onto the still running right engine, with the observed spectacular fire (as one might expect). The rupture of the left side was as planned and AMK was spilled but did not ignite. It seems that the high profile of the CID, with several TV news camera crews in attendance, led to a hasty initial analysis of the observations based on the view from the right-hand side of the plane and ignoring the evidence leading to the above interpretation. Collins and Pinch convey something of this [124] (in the passage cited above) albeit without the essential detail.

However, regardless of the interpretation and misinterpretation of the CID, Landel comments that [125, edited]:

AMK might not have been used even if it were shown to be a miraculous fire suppression agent. There was great concern at some levels in the FAA and certainly in the airline industry. They all expected that if it were accepted in the US it would be imposed all around the world. But how reliable would the additive be, considering the working conditions in airports around the world? The slightly water-sensitive and certainly mechanically degradable antimisting agent would have to be delivered properly, stored properly, mixed properly and transferred properly into the plane. You don't want it to gel in your plane's fuel tank or fuel lines!

so the outcome is perhaps the right one, regrettably if loss of life is deemed preventable by use of AMK. There are object lessons here in relation to communication of scientific and technological ideas to the public and to politicians (in all walks of life).

\section{Concluding remarks}

The literature of the last hundred years has a lot to offer and there are three linked concepts which, it seems likely, will repay further study. These are

- Spinnability

- Separation of elastic and viscous behaviour

- Instability and jet breakup. 
Among recently published work is a review by Larson [35] of polymer solution rheology which has much on extensional flow. It has a good deal to say about DNA molecules in solution as well as the more familiar (to rheologists of a certain age) polystyrene solution. The link with biological fluids is important and the appeal to computational and experimental investigations is characteristic of the best current work. The review by McKinley [17] gives the state of the art for instability and jet breakup, which shows how far one may understand clearly formulated problems with a judicious combination of theory, experiment and computation. The need is to connect the clearly formulated problem(s) with what is actually observed in everyday situations, such as the transition between jetting and dripping [128]. There is a review of the same topic from a mathematical view point by Renardy [129] and of the related topic of rupture of polymer melts in extension by Joshi and Denn [130].

Separation of elastic and viscous behaviour is useful qualitatively but is tricky quantitatively because of nonlinearity. It may be regarded as a convenient simplifying idea with the potential for misleading, though not as much as the inappropriate use of the idea of extensional viscosity. This is discussed in the companion paper [3]. Some classroom demonstrations on the web by McKinley's group [131] are worth looking at even by those who think they are familiar with fluid elasticity in extension. These include a movie showing a simple set-up for Fano flow.

It may be worth drawing attention to a few other odd phenomena which are associated with the flow of jets of complex fluids and the interaction between viscosity, elasticity and surface tension. The "teapot effect" [132] is probably not connected with extensional flow but seems to have had a fascination similar to that of spinnability for some rheologists over a number of years as a report in the New Scientist [133] shows, citing work by M. Reiner (who invokes vorticity, see [134, pp.26-28]) and by J.B. Keller [135]. The kitchen is not far from our minds when we read another paper popularizing science, complete with culinary tips, on the coiling of jets [136] when they fall onto a flat surface such as a pool of the same liquid. The bouncing [137] of a jet raises similar questions about fluid elasticity and surface tension as well as about the mathematical nature of the flow as a boundary-value problem and the particular issue of the influence of down-stream boundary conditions on the flow of the jet as a whole. A quantitative investigation of the coiling (or buckling) of the fluid jet is presented by Cruickshank [138] who refers to earlier work by G.I. Taylor.

Finally we review spinnability: my personal view that it is not adequately understood has drawn protests from those who think that we have made substantial progress in this area over the last century. The main ideas from the first half-century, reviewed above (Section 2.3) are:

1. Pryce-Jones [72] noted that dilatancy (viscosity increasing with rate of 
shear) appears to be essential to spinnability, though not all dilatant systems are spinnable.

2. Scott Blair [84] and Clift [85] remarked on an association between the properties of spinnability and flow-elasticity.

3. Erbring [76] found no clear pattern for the effect of viscosity, surface tension and structure formation on spinnability

4. Erbring found that, in general fibre length increased with spinning velocity and with viscosity. However some materials showed a maximum in spinnability at intermediate viscosity or intermediate spinning velocity.

5. Zidan [82] found that a polyacrylamide solution was spinnable, while a viscose solution failed the Fano test even though both solutions were used to manufacture fibres by spinning.

6. Zidan also claimed that fluids which showed normal stress effects might not be spinnable (industrially), even though they passed the Fano test.

There is clearly an association of spinnability with a high resistance to extensional flow. However it seems highly unlikely that the latter implies the former, nor is it certain that the former implies the latter. One issue which the earlier workers did not address is the distinction between strain-rate hardening in shear and strain-rate hardening in extension; there seemed to be an unwritten assumption that a fluid would be dilatant (strain-rate hardening) or pseudoplastic (strain-rate softening) in all flows. We now know that this is not the case and there is evidence, both from experiment and from theoretical analysis of model viscoelastic fluids, that some fluids are shear-rate softening and extension-rate hardening. The latter property is the one we should associate with spinnability.

One key problem is that there is no agreed quantitative measure of spinnability. Erbring [76] listed three methods (Section 2.3 above) each using the maximum length of a fibre in a particular experiment, but there is no known quantitative connection between these different measures. There is a tendency to think of spinnability as a "yes" or "no" property - a liquid either is spinnable or it is not, in which case the stability or instability of a fibre would be the key property, but this seems to me to be an over-simplification. There is, as the work of Zidan showed, the possibility of a liquid not being spinnable according to one test, yet being used in the manufacture of fibres by spinning. The dependence of some measures of spinnability on spinning velocity reminds us that we may be talking about something which is not strictly a material property.

One is reminded of the nineteenth century use of terms viscosity and internal friction discussed recently by Piau and Piau [139, Section IV] and, in my view, we await some clarity concerning spinnability, though each of us knows what she (or he) means by the term. It seems an obvious conclusion that we need an agreed definition of spinnability as a quantitative term, if we are seriously 
to compare the spinnability of different materials.

I am grateful to a number of friends and colleagues who have contributed to my understanding of extensional flow and its history. Mort Denn, David James, Bob Landel, Gareth McKinley, Art Metzner, Anthony Pearson, Roger Tanner and Ken Walters each have made helpful comments on drafts of this review or have supplied information and encouragement or have done both of these.

\section{References}

[1] F.T. Trouton, On the coefficient of viscous traction and its relation to that of viscosity Proc. Roy. Soc., A77 (1906) 426-440.

[2] G. Fano, Contributo allo studio dei corpi filanti (Contribution to the study of thread-forming materials), Archivio di fisiologio, 5 (1908) 365-370.

[3] C.J.S. Petrie, Extensional viscosity: a critical discussion, J. Non-Newtonian Fluid Mech., This volume (2006).

[4] C.J.S. Petrie Extensional flow in the literature - a naïve assessment, October 2005 ,

http://www.staff.ncl.ac.uk/chris.petrie/papers/petrie06c.pdf (in preparation).

[5] C.J.S. Petrie, Elongational Flows, Pitman (now Longman), London (1979).

[6] R.I. Tanner and K. Walters, Rheology: an Historical Perspective, Elsevier, Amsterdam (1998).

[7] C.J.S. Petrie and J.M. Dealy, Uniform elongational flow of molten polymers, in G. Astarita, G. Marrucci and L. Nicolais (Eds.), Rheology, Volume 1: Principles (Proceedings of the VIIIth International Congress on Rheology), Plenum Press, New York (1980) pp.171-194.

[8] C.J.S. Petrie, Extensional flow - a mathematical perspective, Rheol. Acta, 34 (1995) 12-26.

[9] M.M. Denn, Continuous drawing of liquids to form fibers, Ann. Rev. Fluid Mech., 12 (1980) 365-387.

[10] G.H. McKinley and T. Sridhar, Filament-stretching rheometry of complex fluids, Ann. Rev. Fluid Mech., 34 (2002) 375-415.

[11] M.M. Denn, Extensional Flows: Experiment and Theory, in R.S. Rivlin (Ed.), The Mechanics of Viscoelastic Fluids, AMD-22, ASME, New York, 1977, pp.101-124.

[12] C.J.S. Petrie and M.M. Denn, Instabilities in polymer processing, AIChE J., 22 (1976) 209-236. 
[13] J.R.A. Pearson, Instability of non-Newtonian flow, Ann. Rev. Fluid Mech., 8 (1976) 163-181.

[14] J.L. White, Dynamics, heat transfer and rheologiucal aspects of melt spinning; a critical review, Polym. Eng. Reviews, 1 (1981) 297-362.

[15] C.J.S. Petrie, Some remarks on the stability of extensional flows, Progress and Trends in Rheology, II (1988) 9-14.

[16] R.G. Larson, Instabilities in viscoelastic flows, Rheol. Acta, 31 (1992) 213-263.

[17] G.H. McKinley, Visco-elasto-capillary thinning and break-up of complex fluids, in D.M. Binding and K. Walters (Eds.), Rheology Reviews: 2005, British Society of Rheology, Aberystwyth (2005).

[18] S. Middleman, Modeling axisymmetric flows: dynamics of films, jets, and drops, Academic Press, San Diego (1995).

[19] A.L. Yarin, Free liquid jets and films: hydrodynamics and rheology, Longman, Harlow, (1993).

[20] J.R.A. Pearson, Mechanical Principles of Polymer Melt Processing, Pergamon Press, Oxford (1966).

[21] J.R.A. Pearson, Mechanics of Polymer Processing, Elsevier Applied Science Publishers, London (1985).

[22] S. Middleman, Fundamentals of Polymer Processing, McGraw-Hill, New York (1977).

[23] A. Ziabicki, Fundamentals of Fibre Formation, Wiley-Interscience, London (1976).

[24] A. Ziabicki and H. Kawai (Eds.), High Speed Fibre Spinning, Wiley, New York (1985).

[25] J. Mewis and C.J.S. Petrie, Hydrodynamics of spinning polymers, in N.P. Cheremisinoff (Ed.), Encyclopedia of Fluid Mechanics, Volume 6, Gulf Publishing, Houston (1987) pp.111-139.

[26] S.J. Kurtz, Some key challenges in polymer processing technology, in "Recent Advances in Non-Newtonian Flows", ASME, AMD-Vol 153/PED-Vol 141 (1992) 1-13.

[27] C.J.S. Petrie, Recent ideas in extensional rheology, in J. Becker (Ed.), Polymer Processing Society Europe/Africa Regional Meeting - Extended Abstracts, Chalmers University of Technology, Göteborg, Sweden, (1997) p.KN4:2.

[28] M.J. Crochet, A.R. Davies and K. Walters, Numerical Simulation of NonNewtonian Flow, Elsevier, Amsterdam (1984).

[29] J.R.A. Pearson and S.M. Richardson, (Eds.), Computational Analysis of Polymer Processing, Applied Science Publishers, London (1983). 
[30] J.F. Brady and G. Bossis, Stokesian dynamics, Ann. Rev. Fluid Mech., 20 (1988) 111-157.

[31] R.A. Brown and G.H. McKinley, Report on the VIIIth International Workshop on Numerical Methods in Viscoelastic Flows, J. Non-Newtonian Fluid Mech., 52 (1994) 407-413.

[32] J.K.C. Suen, Y.L. Joo and R.C. Armstrong, Molecular orientation effects in viscoelasticity, Ann. Rev. Fluid Mech., 34 (2002) 417-444.

[33] H.-C. Öttinger, Stochastic Processes in Polymeric Fluids, Springer, Berlin (1996).

[34] T.N. Phillips and R. Owens (Eds.), Proc. XIIIth International Workshop on Numerical Methods for Non-Newtonian Flows, Lausanne, June 2003, J. NonNewtonian Fluid Mech., 122 (2004) 1-337.

[35] R.G. Larson, The rheology of dilute solutions of flexible polymers: Progress and problems, J. Rheol., 49 (2005) 1-70.

[36] J. Meissner, Rheometry of polymer melts, Ann. Rev. Fluid Mech., 17 (1985) 45-64.

[37] J.M. Dealy, Rheometers for Molten Plastics, Van Nostrand Reinhold, New York (1982).

[38] R.K. Gupta and T. Sridhar, Elongational rheometers, in A.A. Collyer and D.W. Clegg, Rheological Measurement, Elsevier Applied Science, London, (1988) pp.211-245.

[39] G.G. Fuller, Optical Rheometry, Ann. Rev. Fluid Mech., 22 (1990) 387-417.

[40] A.Ziabicki, Studies on the orientation phenomenon by fiber formation from polymer melts. II, J. Appl. Polym. Sci., 2 (1959) 24-31.

[41] A. Keller and J.A. Odell, The extensibility of macromolecules in solution; a new focus for macromolecular science, Coll. Polym. Sci., 263 (1985) 181-201.

[42] R.I. Tanner and R.R. Huilgol, On a classification scheme for flow fields, Rheol. Acta, 14 (1975) 959-962.

[43] R.I. Tanner, A test particle approach to flow classification for viscoelastic fluids, AIChE J., 22 (1976) 910-918.

[44] H. Nitschmann and J. Schrade, On the fibre-forming ability of non-Newtonian liquids, Helv. Chim. Acta, 31 (1948) 297-319. see also H. Nitschmann, The viscosity anomaly causing the spinning of liquids: Stress-flow curves of liquid threads, Proc. First Int. Cong. Rheol., (1949) II-32-II-34.

[45] B.D. Coleman, On the use of symmetry to simplify the constitutive equations of isotropic materials with memory, Proc. Roy. Soc., A306 (1968) 449-476.

[46] C.J.S. Petrie, Extensional flows, in D.A. Siginer, D. DeKee and R.P. Chhabra (Eds.), Advances in the Flow and Rheology of Non-Newtonian Fluids, Elsevier, Amsterdam (1999) pp.613-636. 
[47] A.S. Lodge and J. Meissner, Comparison of network theory predictions with stress/time data in shear and elongation for a low-density polyethylene melt, Rheol. Acta, 21 (1973) 41-47.

[48] G.V. Vinogradov, V.D. Fikhman, B.V. Radushkevich and A.Ya. Malkin, Viscolelastic and relaxation properties of a polystyrene melt in axial extension, J. Polym. Sci. A2, 8 (1970) 657-678.

[49] N.R. Doshi and J.M. Dealy, Exponential shear: a strong flow, J. Rheol., 31 (1987) 563-582.

[50] B. Zülle, J.J. Linster, J. Meissner and H.P. Hürlimann, Deformation hardening and thinning in both elongation and shear of a low-density polyethylene melt, J. Rheol., 31 (1987) 583-598.

[51] D.C. Venerus, Exponential shear flow of branched polymer melts, Rheol. Acta, 39 (2000) 71-79.

[52] T.C.B. Kwan, N.J. Woo and E.S.G. Shaqfeh, An experimental and simulation study of dilute polymer solutions in exponential shear flow: comparison to uniaxial and planar extensional flows, J. Rheol., 45 (2001) 321-349.

[53] R.S. Graham, T.C.B. McLeish and O.G. Harlen, Using the pom-pom equations to analyze polymer melts in exponential shear, J. Rheol., 45 (2001) 275-290.

[54] A.B. Metzner, Extensional primary field approximations for viscoelastic media, Rheol. Acta, 10 (1971) 434-444.

[55] D.V. Boger, Viscoelastic flows through contractions, Ann. Rev. Fluid Mech., 19 (1987) $157-182$.

[56] D.F. James and K. Walters, A critical appraisal of available methods for the measurement of extensional properties of mobile systems, in A.A. Collyer (Ed.) Techniques of Rheological Measurement, Elsevier, New York (1994) pp.33-53.

[57] D.F. James, G.M. Chandler and S.J. Armour, A Converging Channel Rheometer for the Measurement of Extensional Viscosity, J. Non-Newtonian Fluid Mech., 35 (1990) 421-443.

[58] F.N. Cogswell, Converging flow and stretching flow: a compilation J. NonNewtonian Fluid Mech., 4 (1978) 23-38.

[59] D.M. Binding and K. Walters, On the use of flow through a contraction in estimating the extensional viscosity of mobile polymer solutions, J. NonNewtonian Fluid Mech., 30 (1988) 233-250.

[60] Society of Rheology, J. Rheol., Volume 1, Issue 1 (1929) 1-122.

[61] British Society of Rheology, Bulletin, Volume 27, Issue 1 (1984).

[62] J.L. White, Dynamics and structure development during melt spinning of fibers, J. Soc. Rheol. Japan, 4 (1976) 137-148.

[63] Obituary Notices of Fellows deceased, Proc. Roy. Soc., A110 (1926) iv-ix. 
[64] Frederick Trouton, On molecular latent heat, Phil. Mag. (Ser. 5) 18 (1884) 54-57.

[65] F.T. Trouton and E.S. Andrews, On the viscosity of pitch-like substances, Phil. Mag. (Ser. 6), 7 (1904) 347-355.

[66] F.T. Trouton and A.O. Rankine, On the stretching and torsion of lead wires beyond the elastic limit, Phil. Mag. (Ser. 6) 8 (1904) 538-556.

[67] C. Pogliano, Filosofia dei medici e medicina filosofia: due 'casi' tra ottocento e novecento, Giornale Critico della Filosofia Italiana, 3 (1983) 340-359.

[68] A.Ya. Malkin and C.J.S. Petrie, Some conditions for rupture of polymer liquids in extension, J. Rheol., 41 (1997) 1-25.

[69] anon., British Rheologist's Club Inaugural Meeting, Nature, 146 (1940) 781.

[70] V.G.W. Harrison, The science of rheology, Nature, 146 (1940) 580-582.

[71] Bulletin of the British Rheologist's Club, Issue 1 (1940)

[72] J. Pryce-Jones, Experiments on thixotropic and other anomalous fluids with a new rotation viscometer, J. Sci. Instr., 18 (1941) 39-48.

[73] J. Pryce-Jones, Studies in thixotropy, Koll.-Z., 129 (1952) 96-122.

[74] A.G. Ward, Rheology of proteins (BSR symposium report), Nature, 177 (1956) 516-517.

[75] H. Erbring, Über Spinnbarkeit von Flüssigkeiten, V: Einige Beobachtungen an Polystyrolfäden (On the spinnability of fluids, V: Some observations on polkystyrene fibres), Koll.-Z., 82 (1938) 132-134.

[76] H. Erbring, Untersuchungen über die Spinnbarkeit flüssiger Systeme (Investigations of the spinnability of fluid systems), Koll.-Beih., 44 (1936) 171237.

[77] H. Erbring, Zur Kenntnis der Spinnbarkeit lyophiler kolloider Lösungen sowie der mechanischen Eigenschaften der aus diesen hergestellten festen Fäden (Information on the spinnability of lyophilic colloidal solutions and mechanical propereties of solid fibres prepared from them) II, Koll.-Z., 77 (1936) 32-36.

[78] H. Erbring, Über Spinnbarkeit von Flüssigkeiten (On the spinnability of liquids) (Part III), Koll.-Z., 77 (1936) 213-219.

[79] A. Aggazotti, Modificazioni della viscosita della saliva mista dopo che e stata secreta in rapporto col potere filante e colla tensione superficiale (Modifications of the viscosity of saliva :. in connection with spinnability and surface tension), Arch. Fisiol., 20 (1922) 3-15.

[80] G. Tammann and R. Tampke, Über die Spinnfähigkeit, Oberflächenspannung und die spezifische Wärme von Gläsern (On the spinnability, surface tension and specific heat of glasses), Z. anorg. allgem. Chem., 162 (1927) 1-16. 
[81] J. Jochims, Über die Spinnbarkeit physiologischer Flüssigkeiten und über die Methoden ihrer Messung (On the spinnability of physiological fluids and on methods of its measurement), Koll.-Z., 61 (1932) 250-256.

[82] M. Zidan, Zur Rheologie des Spinnprozesses (On the rheology of the spinning process), Rheol. Acta, 8 (1969) 89-123.

[83] D'Arcy Wentworth Thompson, On Growth and Form (Abridged Edition), Cambridge University Press, (1961).

[84] G.W. Scott Blair, S.J. Folley, F.H. Malpress and F.M.V. Coppen, Variation in certain properties of bovine cervical mucus during the oestrus cycle, Biochem. J., 35 (1941) 1039-1049.

[85] A.F. Clift, Observations on certain rheological properties of human cervical secretion, Proc. Roy. Soc. Med., 39 (1945) 1-9.

[86] P.-O. Glantz, R.E. Baier and C.E. Christersson, Biochemical and physiological considerations for modeling biofilms in the oral cavity: A review, Dent. Mater., 12 (1996) 208-214.

[87] R.G. Larson, Spinnability and viscoelasticity, J. Non-Newtonian Fluid Mech., 12 (1983) 303-315.

[88] First Report on Viscosity and Plasticity, Prepared by the Committee for the Study of Viscosity of the Academy of Sciences at Amsterdam, Verhandelingen der Koninklijke Akademie van Wetenschappen te Amsterdam Afdeeling Natuurkunde (Eerste Sectie) Deel XV No. 3, North Holland (1935).

[89] Second Report on Viscosity and Plasticity, Prepared by the Committee for the Study of Viscosity of the Academy of Sciences at Amsterdam, Kon. Ned. Akad. Wet., Verhand. (Eerste Sectie), Dl. XVI, No.4 (1938) 1-287.

[90] C.J. van Nieuwenburg, Viscosity and plasticity from a technical point of view, Ch. IV in First Report on Viscosity and Plasticity, Academy of Sciences, Amsterdam (1935) pp.141-172.

[91] J.M. Burgers, Mechanics, models, ...(Ch. I), Experiments, (Ch. II), in First Report on Viscosity and Plasticity, Academy of Sciences, Amsterdam (1935).

[92] J.D. van der Waals Jr., Verslagen Akad. Amsterdam, 27 (1918/19) 744, 1350. alternatively Proceedings, 21 (1918/19) 743, 1283.

[93] E.N.da C. Andrade, On the viscous flow in metals and allied phenomena, Proc. Roy. Soc., A84 (1910) 1-12. see also Proc. Roy. Soc., A90 (1914) 329.

[94] E.C. Bingham, J. Franklin Inst., 197 (1924) 105.

[95] G.I. Taylor and W.S. Farren, Proc. Roy. Soc., A111 (1926) 531.

[96] J.R. Scott, Theory and application of the parallel-plate plastometer, Trans. IRI, 7 (1931) 169-186. 
[97] H.R. Lillie, Viscosity of glass between the strain point and the melting temperature, J. Amer. Ceram. Soc., 14 (1931) 502-511.

See also H.R. Lillie, J. Amer. Ceram. Soc., 16 (1933) 619.

[98] E.C Bingham, Fluidity and Plasticity, McGraw Hill, New York (1922).

[99] K. Weissenberg, Recent advances in the goniometry of flow, Bulletin of the British Society of Rheology, No.43 (April 1955) p.6.

[100] R.L.Ballman, Extensional flow of polystyrene melt, Rheol. Acta4 (1965) 137140.

[101] J.Meissner, Rheometer zur Untersuchung der deformationsmechanischen Eigenschaften von Kunststoff-Schmelzen unter definierter Zugbeanspruchung (A rheometer for investigation of deformation-mechanical properties of plastic melts under defined extensional straining), Rheol. Acta, 8 (1969) 78-88.

[102] F.N. Cogswell, The rheology of polymer melts under tension, Plast. Polym., 36 (1968) 109-111.

[103] G.V. Vinogradov, B.V. Radushkevich and V.D. Fikhman, Extension of elastic liquids: polyisobutylene, J. Polym. Sci. A2, 8 (1970) 1-17.

[104] G.V. Vinogradov and A.Ya. Malkin, Reologiya Polimerov, Chimiya, Moscow, (1977).

[105] G.V. Vinogradov and A.Ya. Malkin Rheology of Polymers (translated and updated) Mir, Moscow (1979).

[106] J.E. Shelby, Introduction to Glass Science and Technology, Royal Society of Chemistry, Cambridge (1997).

[107] D.C. Bogue and J.L. White (Eds.), Special Issue - Symposium on Fiber Rheology and Spinning held at the 42nd Annual Society of Rheology Meeting, Knoxville, 27th-28th October, 1971, J. Rheol.(Transactions of the Society of Rheology), 16 (1972) 381-576.

[108] J.M. Dealy, Official nomenclature for material functions describing the response of a viscoelastic fluid to various shearing and extensional deformations, J. Rheol., 28 (1984) 181-195.

[109] J.M. Dealy, Official nomenclature for material functions describing the response of a viscoelastic fluid to various shearing and extensional deformations. Reprinted version with additions and corrections, J. Rheol., 38 (1994) 179-191.

[110] British Society of Rheology, Conference Summaries, Rheol. Abs., 16 (1973) 169-173.

[111] British Society of Rheology, Conference Summaries, Rheol. Abs., 18 (1975) 106-108.

[112] Stretching Flows Proceedings of part of the British Society of Rheology Conference, Edinburgh, 7th-9th September, 1977, J. Non-Newtonian Fluid Mech., 4 (1978) 3-166. 
[113] Extensional Flows including papers from the Conference of the British Society of Rheology and the Societá Italiana di Reologia, Newcastle upon Tyne, 8th10th September, 1981, J. Non-Newtonian Fluid Mech., 11 (1982) 217-299.

[114] Proceedings of an International Conference on Extensional Flow, held at Chamonix, France, 18th-22nd January, 1988, J. Non-Newtonian Fluid Mech., 30 (1988) 97-368.

[115] Proceedings of an International Conference on Extensional Flow, held at Combloux, France, 20th-23rd March, 1989, J. Non-Newtonian Fluid Mech., 35 (1990) 85-470.

[116] N.E. Hudson and T.E.R. Jones, The A1 project - an overview, J. NonNewtonian Fluid Mech., 46 (1993) 69-88.

[117] Proceedings of a meeting on the Rheometry of Polymers, from the Solution to the Melt, held at the Abbaye Royale de Fontevraud, France, 12th-15th May, 1993 J. Non-Newtonian Fluid Mech., 52 (1994) v, 105-288

[118] S.T.J. Peng and R.F. Landel, Rheological behavior of FM-9 solutions and correlation with flammability test results and interpretations, J. Non-Newtonian Fluid Mech., 12 (1983) 95-111.

[119] S.T.J. Peng and R.F. Landel, Preliminary investigation of elongational flow of dilute polymer solutions, J. Appl. Phys., 47 (1976) 4255-4260.

[120] E.P. Klueg, B.C. Fenton and S.L. Imbrogno, Aircraft fire safety research with antimisting fuels - Status report, 18th AIAA, SAE and ASME Joint Propulsion Conference, Cleveland, OH, June 21-23, 1982,

http://www.aiaa.org/content.cfm?pageid=406\&gTable=mtgpaper\&gID=44469 and http://pdf.aiaa.org/preview/1982/PV1982_1235.pdf

[121] V. Sarohia, P. Parikh, A. Yavrouian and E. Matthys, Research on antimisting fuel for suppression of postcrash aircraft fires, 24th AIAA Aerospace Sciences Meeting, Reno, NV, Jan. 6-9, 1986,

http:/ www.aiaa.org/content.cfm?pageid $=406 \&$ gTable $=$ mtgpaper\&gID $=91012$ and http://pdf.aiaa.org/preview/1986/PV1986_573.pdf

[122] Index of still photographs from the CID project, http://www.dfrc.nasa.gov/Gallery/Photo/CID/index.html

[123] Controlled Impact Demonstration (CID) flight video montage [NASA Gallery], http://www.dfrc.nasa.gov/Gallery/Movie/CID/HTML/EM-0004-03.html

[124] Massimo Pigliucci, Review of "The Golem at Large: What You Should Know About Technology" by Harry Collins and Trevor Pinch, Cambridge University Press (1998)

http://life.bio.sunysb.edu/ massimo/reviews/Collins\&Pinch.html

[125] R.F. Landel, personal communication (May 2005). 
[126] CID Aircraft post-impact lakebed skid, Text associated with a CID still photograph (one of a number with similar URLs),

http://nix.ksc.nasa.gov/info?id=EC84-31806\&orgid=7

[127] Film from tail-mounted camera of the CID impact (one of a number with similar URLs),

http://lisar.larc.nasa.gov/MOVIES/SMALL/LV-1998-00099.mov

[128] Front cover, BSR Bulletin, vol. 47, issue 1 (2005).

[129] M. Renardy, Self-similar breakup of non-Newtonian liquid jets, in Rheology Reviews, 2004, D.M. Binding and K. Walters (Eds.), British Society of Rheology, Aberystwyth (2004) pp.171-196.

http://www.bsr.org.uk/

[130] Y.M. Joshi and M.M. Denn, Failure and recovery of entangled polymer melts in elongational flow, in Rheology Reviews, 2004, D.M. Binding and K. Walters (Eds.), British Society of Rheology, Aberystwyth (2004) pp.1-17.

http://www.bsr.org.uk/

[131] G.H. McKinley et al., Non-Newtonian flow demonstrations, http://web.mit.edu/nnf

[132] E.T. White, C.R. Greig, J.E. Lehane and J.R. Maughan, The teapot effect, CHEMECA 87, Melbourne, vol. 2, pp.72.1-72.7 (1987).

[133] Anon., Up the Spout, New Scientist, 15th August 1957, reprinted in Tiny Science, Chapter 12 of Bizarre Tales from the New Scientist, A. Anderson \& M. O'Hare (Eds.), Reed Business International, London (1998) p.42.

[134] M. Reiner, Deformation, Strain and Flow, (Second edition), H.K. Lewis, London (1960).

[135] J.B. Keller, Teapot effect, J. Appl. Phys., 28 (1957) 859-864.

[136] J. Walker, The Amateur Scientist: Why do honey and syrup form a coil when they are poured?, Scientific American, 245, No.3 (September 1981) 158-168.

[137] S. Nigen and K. Walters, On the two-dimensional splashing experiment for Newtonian and slightly elastic liquids, J. Non-Newtonian Fluid Mech., 97 (2001) 233-250.

[138] J.O. Cruickshank and B.R. Munson, An energy loss coefficient in fluid buckling, Phys. Fluids, 25 (1982) 1935-1937.

[139] J.-M. Piau and M. Piau, Comment on "Origin of concentric cylinder viscometry". The relevance of the early days of viscosity, slip at the wall and stability in concentric cylinder viscometry, J. Rheol., 49 (2005) 1539-1550. 